\title{
Mechanical properties of potato starch modified by moisture content and addition of lubricant**
}

\author{
Mateusz Stasiak ${ }^{1 *}$, Marek Molenda ${ }^{1}$, Józef Horabik ${ }^{1}$, Peter Mueller ${ }^{2}$, and Ireneusz Opaliński ${ }^{3}$ \\ ${ }^{1}$ Institute of Agrophysics, Polish Academy of Sciences, Doświadczalna 4, 20-290 Lublin, Poland \\ ${ }^{2}$ Department of Mechanical Process Engineering, Otto-von-Guericke University, Universitätsplatz 2, 39106 Magdeburg, Germany \\ ${ }^{3}$ Department of Chemical and Process Engineering, Rzeszów University of Technology, Al. Powstańców Warszawy 12, \\ 35-959 Rzeszów, Poland
}

Received December 15, 2013; accepted June 18, 2014

\begin{abstract}
A b s t r a c t. Laboratory testing was conducted to deliver a set of characteristics of structure and mechanical properties of pure starch and starch with an addition of a lubricant - magnesium stearate. Considerable influence of moisture content of potato starch was found in the case of density, parameters of internal friction, coefficients of wall friction and flowability. Elasticity was found to be strongly influenced by water content of the material. Addition of magnesium stearate affected density and parameters of flowability, internal friction and elasticity. Bulk density increased from 604 to $774 \mathrm{~kg} \mathrm{~m}^{-3}$ with decrease in moisture content of potato starch from 17 to for $6 \%$. Addition of magnesium stearate resulted in approximately $10 \%$ decrease in bulk density. Angle of internal friction obtained for $10 \mathrm{kPa}$ of consolidation stress decreased from 33 to $24^{\circ}$ with increase in moisture content, and to approximately $22^{\circ}$ with addition of the lubricant. With an increase of moisture content from 6 to $18 \%$ and with addition of the lubricant, the modulus of elasticity during loading decreased from approximately 1.0 to $0.1 \mathrm{MPa}$. Modulus of elasticity during unloading was found in the range from 19 to $42 \mathrm{MPa}$ and increased with increase of moisture content and amount of lubricant.

K e y w o r d s: potato starch, mechanical properties, friction, elasticity
\end{abstract}

\section{INTRODUCTION}

The volume and range of materials in powdered form are still increasing in industry, yet simultaneously powder handling remains one of the least understood areas associated with solid processing plants. Scientific knowledge regarding powder technology is still fragmentary, design of equipment relies on empirical concepts, and process control is largely based on experts know-how (Cuq et al., 2011; Moya et al., 2013; Stasiak et al., 2010). Predictable process-

\footnotetext{
*Corresponding author e-mail: mstasiak@ipan.lublin.pl

**This work was financed from the budget for science as research project No. N 313141938 (2010-2013).
}

ing, assuring quality and reduction of losses of products, are still substantial issues. Increasing scale of industrial operations requires the design of efficient equipment and reliable processes that in turn calls for more precise information about the physical characteristics of substrates (Mazurkiewicz, 2011; Ramirez et al. 2009; Stasiak et al., 2007).

One of the frequently used powdered materials all over the world is potato starch, as cheap and easily available. With the market share of $6 \%$ in the world, it is one of the major components in the formulation of food products. Starch is one of the most widely used excipients in manufacture of solid dosage form as binder and dissenter in tablets formulation (Ahmad et al., 2012; Odeku et al., 2005; Ruppel et al., 2009; Wang et al., 2010). Starch is a useful raw material for biodegradable thermoplastics because of its natural abundance and low cost (Mitrus and Mościcki, 2009; Mościcki et al., 2012; Zavareze et al., 2012). However, its low flowability and hydrophilicity generate serious technological problems. That is why in formulations for thermoplastics production flows, agents are used to improve flowability and to change characteristics from hydrophilic to hydrophobic (Chujiang et al., 2009). These authors proposed a new dry process for the production of hydrophobic corn starch without solvent. To find the origins of properties of starch powders, investigations focused on single granule properties have been conducted. Schroeter et al. (1992) obtained parameters of potato starch measured on single granule. Elastic modulus of $2.7 \mathrm{GPa}$, tensile strength of $62 \mathrm{MPa}$, indentation hardness of $113 \mathrm{MPa}$ found by these authors were in a range of values of those obtained for rigid thermoplastics. Salerno et

(C) 2014 Institute of Agrophysics, Polish Academy of Sciences 
al. (2014), in their atomic force microscope examinations of individual granules, obtained elastic modulus of potato starch of $9.8 \mathrm{MPa}$, thus fairly close considering usually high variability of properties of materials of biological origin.

Numerous research projects have been performed to study the mechanical properties of biopolymers such as starch, and the influence of various process parameters on these properties (Mitrus and Mościcki, 2009; Mościcki et al., 2012; Zavareze et al., 2012) as well as properties of tablets made with starch components (Odeku et al., 2005). Most frequently addressed issues are: internal friction, flowability, elasticity and friction (including slip-stick effect). These parameters are of high importance in technologies including compression, like extrusion and tablet production, where pressure in equipment determines the necessary strength of construction members of installation. Magnesium stearate is widely used in tablet formulation because of its lubrication action and ability to form hydrophobic thin film on the surface of the carrier granules. Use of magnesium stearate allows to reduce power consumption and ejection forces in tablet production (Wang et al., 2010). Another factor determining the mechanical behaviour of powders is moisture content that affects flowability, cohesion, caking, density, shear strength, compaction and compression characteristics (Nokhodchi, 2005).

Di Qu et al. (1998) investigated the influence of normal pressure, degree of conversion of starch, effective shear rate, temperature and moisture content on shear stress in the powder to obtain an equation combining all above effects. Waxy corn starch was tested in modified vane shear test device and fairly good correlation between calculated and shear resistance was obtained. Ruppel et al. (2009) examined flowability of corn starch powder with different additions of a flow regulator used in the pharmaceutical industry. Housner ratio and shear stress of mixtures were measured, moreover flowability parameters were determined using modified outflow funnel. The authors determined the conditions of best flow behaviour with the addition of flow agent and compared the new method of flowability determination with those well established.

Fitzpatrick and Ahrne (2005), in an article that summarized a 1-year project focusing on food powder handling and processing, point out that food powders characterization, design of powder storage and transport is the most important knowledge barrier in industry and a major research need.

Numerical modelling is a promising but just emerging tool for the design of processes of powder technology that require specific material parameters. One of currently developing approaches is DEM - discrete element method. Di Qu et al. (1998) used DEM for modelling of extrusion and tableting processes; that task also required knowledge of material properties, transport phenomena and kinetics of reaction.
The objective of the reported project was to deliver a set of structural and mechanical characteristics of potato starch of different moisture contents and with the addition of a lubricant. The modulus of elasticity, the slip-stick effect, the angle of internal friction, the cohesion, flowability and friction against typical construction materials were determined. The data presented may be useful in design of equipment and control of processes in the industrial handling and conveying of potato starch.

\section{MATERIAL AND METHODS}

Commercial potato starch with moisture content of 6 , 12 and 17\%, produced by Melvit in Ostrołęka, Poland, was used as the experimental material. Particle size distribution was analyzed using the Infrared Particle Sizer IPS UA (Kamika, 2009). The method consists in measurement, in continuous and graduated manner, of changes of laser radiation stream scattered by moving particles in the air. The parameters are defined as follows: the mean diameter for a given amount of particles $\left(D_{n}\right)$, the mean geometric diameter $\left(\mathrm{D}_{\mathrm{geo}}\right)$, the size at which $50 \%$ of the sample is smaller and $50 \%$ is larger $\left(\mathrm{D}_{\text {med }}\right)$, the form factor which is the ratio of two dimensions (height/width) of a single particle (WK) (for the sphere $\mathrm{WK}=1$ ) (Kamika, 2009).

Moistening of the powder was realized by humidifier in closed cubic space for $48 \mathrm{~h}$. Moisture content(MC) (wetbasis) was measured gravimetrically by weighing $10 \mathrm{~g}$ of sample before and after drying at $105^{\circ} \mathrm{C}$ for $24 \mathrm{~h}$. Dried materials were obtained by $24 \mathrm{~h}$ drying in laboratory drier with forced air circulation in stable temperature of $30^{\circ} \mathrm{C}$. The characteristics of the starches were quantified at the levels of moisture content occurring in practical technological processes.

Carr parameters with indexes describing flowability were determined using Powder Characteristics Tester PT-S, Hosokawa (Carr, 1965). Aerated density $\left(\rho_{\text {aer }}\right)$ is a bulk density of particulate containing much air built up in a vessel by dropping according to the injection method. The packed density $\left(\rho_{\text {pack }}\right)$ is a bulk density of particulate of loose bulk density built up by tapping. The compressibility (Co) is determined by the measurement of aerated and packed bulk densities. As the compressibility is higher, the flowability is poorer. The angle of repose $\left(\varphi_{\text {rep }}\right)$ means an angle of heap of particulate built up by dropping according to the injection method. Particulate poor in flowability shows a wide angle of repose. The angle of fall $\left(\varphi_{\text {fall }}\right)$ means an angle of residual particulate heap resulting from collapse due to application of a certain shock to the particulate forming the angle of repose. As the particulate is more liable to flow spontaneously, the angle of fall is narrower. The angle of difference $\left(\varphi_{\text {diff }}\right)$ is the difference between the angle of repose and the angle of fall. As the angle of difference is wider, the flushing phenomenom is more likely to occur. Electron scanning microscope examinations were performed using the JSM 5200 microscope at $10 \mathrm{keV}$. Specimens were placed on double-side adhesive tape mounted on aluminium specimen holders, coated with gold in vacuum evaporator JEOL 400. 
Magnesium stearate was used as the lubricant in amounts of 1,2 and $6 \%$ of weight of the potato starch sample and mixed for $1 \mathrm{~h}$ in standard laboratory mixer. This chemical is a widely used lubricant for tablet compression because of its expedient mechanical properties: low coefficient of friction, very small particles and hydrophobic properties (Wang et al., 2010).

Direct shear tests were performed in a shear box $60 \mathrm{~mm}$ in diameter. The tests followed Eurocode 1 (2006) standard procedure for consolidation reference stresses $\left(\sigma_{\mathrm{r}}\right)$ of 4 , 6 and $10 \mathrm{kPa}$ and speed of shearing (V) of $0.035 \mathrm{~mm} \mathrm{~s}^{-1}$. Based on the experimental curves, the angle of internal friction $(\varphi)$, the effective angle of internal friction $(\delta)$, flow functions $(\mathrm{FF})$, cohesion $(\mathrm{C})$, wall friction coefficient $(\mu)$ on black, galvanized and stainless steel samples were determined. Yield locus was determined based on the values of the maximum shear stresses at two levels of consolidation stress as recommended by Eurocode 1 (2006). Next, Mohr circles were drawn, which provided a basis for calculating the values of unconfined yield strength and major consolidating stress. The relationship between these two parameters regarded as FF, was also calculated (Molenda et al., 2006).

Prototype uniaxial compression tester with horizontal stress control was used to determine poured bulk density $(\rho)$, bulk density of consolidated material $\left(\rho_{\text {cons }}\right)$, modulus of elasticity (E) during loading and unloading and Poisson ratio $v$. Maximum consolidation stress of $10 \mathrm{kPa}$ was applied as recommended by Eurocode 1 and incremental value of vertical stress was $2 \mathrm{kPa}$. The uniaxial compression tester is presented in Fig. 1. Supports of two basic components of the tester: force transducer and of electronic micrometer are mounted on the duralumin base, on which also the cylindrical chamber of the apparatus is placed. Cylindrical chamber, $25 \mathrm{mmm}$ high and $60 \mathrm{~mm}$ in diameter, consists of two semicircular halves connected with hinge. One of the halves is connected rigidly to the bottom plate, while the second one is connected with the structure through a force transducer to restore the shape of the cylinder. Top and bottom bases of the chamber are rigid at the load level applied and their inner surfaces are smooth.
Consolidation stress was enforced gravitationally through a yoke which is placed on the top plate of the chamber. The height of sample and its changes were measured by electronic micrometer with the accuracy of $0.001 \mathrm{~mm}$. A vertical stress is applied to the sample constrained against horizontal deformation. As the vertical stress increases, the change in induced horizontal stress and the change in vertical displacement is measured. The $\mathrm{E}$ for loading is calculated from thesemeasurements. Theverticalstress shouldthenbedecreased and the change in induced horizontal stress and the change in vertical displacement is measured and from these data $\mathrm{E}$ for unloading is calculated. Details of the procedure of determination of modulus of elasticity during loading and unloading were as described in Eurocode 1 (2006).

\section{RESULTS AND DISCUSSION}

Microscopic images and results of size analysis are presented in Fig. 2. The granules are characterized by bimodal shape, typical for potato starch, and rather broad range of diameters. Surfaces of the granules are smooth and diameters range from 5 to $70 \mu \mathrm{m}$. Large granules are elongated in shape, whereas the small ones are closer to circular. These results are in good agreement with the wide research of Bieganowski et al. (2011) focusing on the geometry of potato starch granules. These results corroborate results of earlier investigation that potato starch granules are oval and irregular or cuboidshaped while corn and wheat starch granules are angular, spherical and lenticular-shaped (Singh et al., 2003).

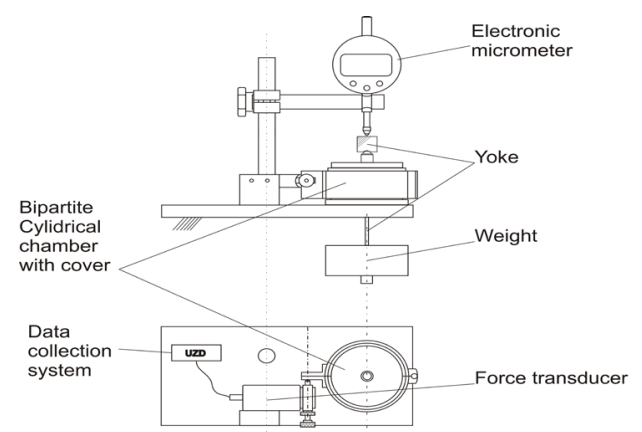

Fig. 1. Prototype uniaxial tester with measurement of horizontal stress.

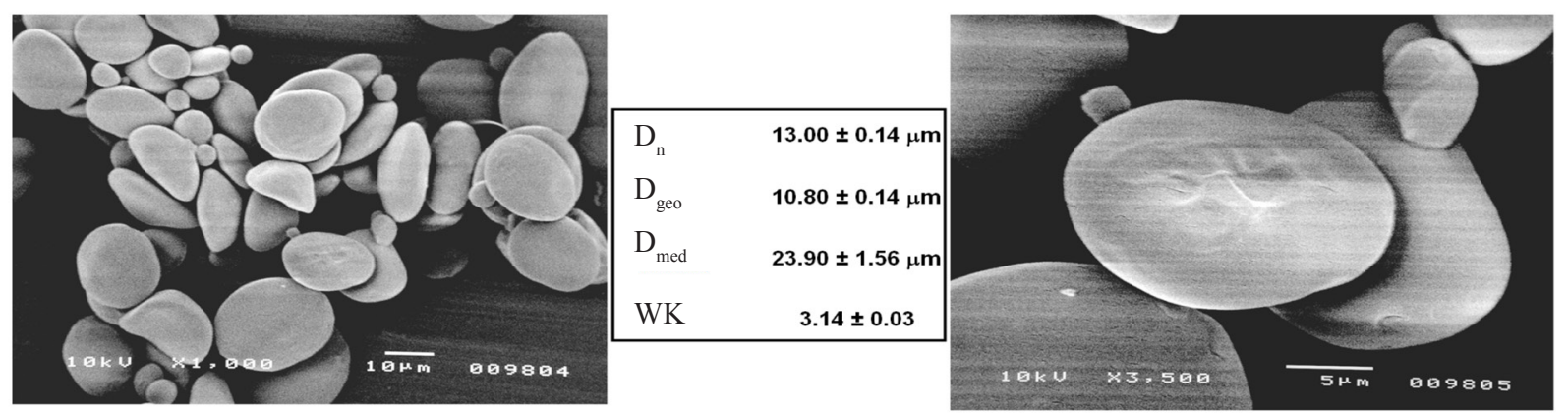

Fig. 2. Microscopic images and UPS Kamika particle size analysis of potato starch (Stasiak et al., 2011). 
The presence of granules with diverse shape and size can strongly influence the physical properties and behaviour of the powder during processing. Baldwin et al. (1998), based on AFM images, have shown that the surfaces of wheat and potato starch granules present substantially different topographies. Potato starch granules have a rougher surface than that of wheat starch granules, consisting of large raised nubs (50 to $300 \mathrm{~nm}$ in diameter) above a flatter surface containing structures of diameters from approximately 10 to $50 \mathrm{~nm}$. The value of $\mathrm{D}_{\mathrm{n}}$ was $13 \mu \mathrm{m}, \mathrm{D}_{\text {geo }} 10.8 \mu \mathrm{m}$ and the form factor of potato starch was approximately 3 .

Moisture content was found to influence strongly the density of potato starch. Poured and consolidated density determined in uniaxial chamber decreased with an increase of moisture content from 774 to 604 and from 895 to $788 \mathrm{~kg} \mathrm{~m}^{-3}$, respectively.

Density decreased also with the addition of magnesium stearate to potato starch, at $6 \% \mathrm{MC}$ and resulted in a decrease of poured density to about $730 \mathrm{~kg} \mathrm{~m}^{-3}$ with the addition of 2 and $6 \%$ of the lubricant. No influence of the addition of the lubricant on consolidated density was observed (Table 1). This result is contrary to what should be expected from the addition of lubricant and what is observed in tableting. The possible explanation of such behaviour is the large difference in pressure level of $10 \mathrm{kPa}$ in compaction testing compared to about $10 \mathrm{MPa}$ in tablet formation. Probably, at high level of pressure, deformation or even breakage of granules take place that are facilitated by the action of
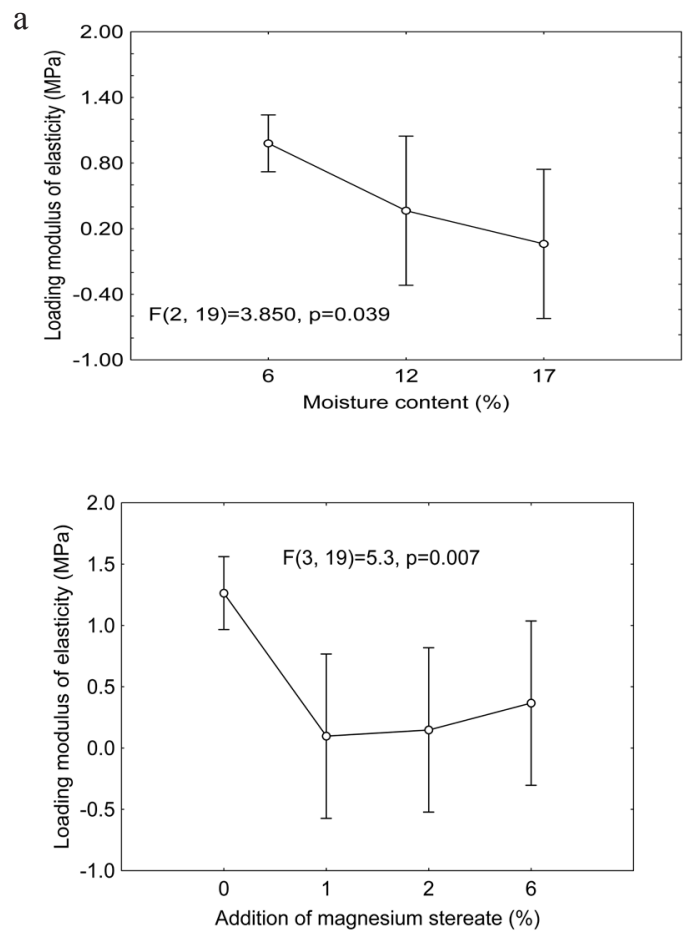

lubricant. At low pressure level, the addition of magnesium stearate would oppose or did not influence compaction. These results are also in opposite to results obtained by Bos et al. (1987). In their investigation the density of lubricated potato starch were $900 \mathrm{~kg} \mathrm{~m}^{-3}$ during unlubricated $708 \mathrm{~kg} \mathrm{~m}^{-3}$.

T a b l e 1. Density of potato starch determined in uniaxial chamber

\begin{tabular}{ccc}
\hline & $\begin{array}{c}\text { Poured } \\
\text { density } \\
\text { Parameter }\end{array}$ & $\begin{array}{c}\text { Consolidated } \\
\text { density } \\
\rho_{\text {cons }}\end{array}$ \\
\cline { 2 - 3 } Moisture content (\%) & \multicolumn{2}{c}{$\left(\mathrm{kg} \mathrm{m}^{-3}\right)$} \\
6 & $774 \pm 1$ & $895 \pm 3$ \\
12 & $665 \pm 1$ & $817 \pm 21$ \\
17.5 & $604 \pm 15$ & $788 \pm 26$ \\
Addition of magnesium & & \\
stearate $(\%)$ & & $895 \pm 3$ \\
1 & $774 \pm 1$ & $861 \pm 21$ \\
2 & $698 \pm 11$ & $904 \pm 22$ \\
6 & $731 \pm 9$ & \\
\hline
\end{tabular}

b
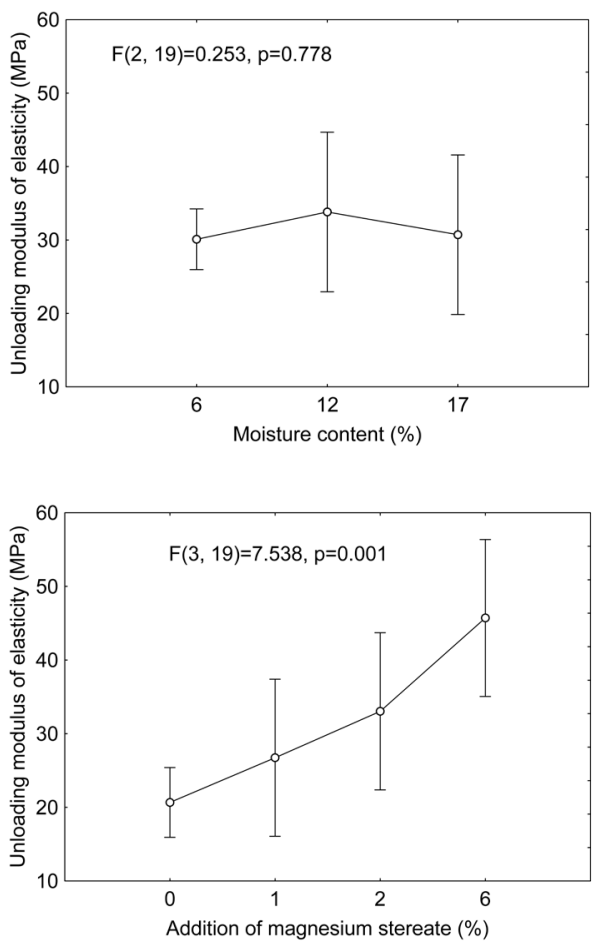

Fig. 3. Modulus of elasticity for: $a$ - loading and b - unloading as a function of powder moisture content and amount of lubricant addition. Points denote mean values and vertical bars denote the 0.95 confidence intervals; F, p - analysis of variance parameters. The higher value of test function $\mathrm{F}$ means than given effect has stronger influence on determined parameter. The p-value is significance. 
Moduli of elasticity $\left(\mathrm{E}_{\mathrm{lo}}\right)$ and $\left(\mathrm{E}_{\mathrm{un}}\right)$ determined following Eurocode1 recommendation in prototype uniaxial tester are shown in Fig. 3. There is still need for developing new device for the measurements of parameters of powdered materials. One of such device is that proposed by Barletta and Poletto (2013) who invented two half-cells with fixed one and mobile one using a single standard load cell without the need to apply strain gauges on custom built parts, as in apparatus presented in this article. Values of the parameter obtained under the loading regime were approximately 30 times lower than those for unloading. Modulus of elasticity during loading, $\mathrm{E}_{10}$, decreased from approximately 1 to $0.1 \mathrm{MPa}$ with an increase of moisture content from 6 to $17 \%$. No influence of MC was observed for unloading modulus of elasticity. The high scatter of results observed in these examinations allows for concluding about tendencies rather than firm relationships.

Loading modulus of elasticity decreased strongly from about $1 \mathrm{MPa}$ to about $0.1 \mathrm{MPa}$ with addition of the lubricant (Fig. 3). Further increase in the addition of magnesium stearate did not influence the behaviour of this parameter. Opposite tendency was observed for unloading where increasing amount of the lubricant resulted in an increase in modulus of elasticity. The average values of unloading modulus increased from approximately $20 \mathrm{MPa}$ without the lubricant up to approximately $45 \mathrm{MPa}$ with the highest addition of the lubricant. Results of this parameter for single granules obtained by Salerno et al. (2014) is ten time higher from loading modulus.

Carr indexes of potato starch are presented in Table 2. The angle of repose strongly increased with growing moisture content of powder, from $38^{\circ}$ for $6 \%$ moisture content of powder to $58^{\circ}$. The softest cone formed with powder was obtained for potato starch with $12 \%$ of moisture content (angle of difference $28^{\circ}$ ). The addition of magnesium stearate also resulted in an increase in the angle of repose, but only a weak tendency was observed. The most unstable powder cone was obtained for the highest addition of the lubricant. In the case of material with the lubricant higher values of aerated density were found, but still lower than in uniaxial compression test. Aerated bulk density was found equal to this obtained in uniaxial compression and decreasing with an increase in moisture content from 6 to $17 \%$ adequately from 763 to $593 \mathrm{~kg} \mathrm{~m}^{-3}$. Packed bulk density was higher than consolidated density (Table 2). This is the effect of stronger compaction using tapping in the whole mass of sample compared to compression through the top plate of uniaxial compression tester. Probably in the uniaxial compression apparatus layers of powder close to the upper lid were consolidated stronger than those close to the bottom of the chamber as an effect of friction acting on the wall. The highest compressibility equal to 30 was obtained for powder with the highest moisture content. These value was nearly equal to compressibility of the material with an addition of the lubricant, where the amount of magnesium stearate added did not influence the result. Similar investigations were performed by Crouter and Briens (2014). Authors stated that flowability determined by Carr indexes decreased with increasing moisture content, once critical point $f$ monolayer water coverage was reached, due to an increase in cohesion from stronger interparticle liquid bridges.

Experimental relationships obtained in direct shear tester are presented in Fig. 4. Strong disturbances of friction force were observed in the case of $6 \% \mathrm{MC}$. potato starch for consolidation stresses of 4, 6 and $10 \mathrm{kPa}$. Such fluctuations of experimental relationships observed in mechanical systems with frictional damping are termed the slip-stick effect and are attributed to the difference between coefficients of static and dynamic friction (Abdo et al., 2010). Fluctuations could be the reason of surface condition of single particles

T a b l e 2. Carr indexes of potato starch

\begin{tabular}{|c|c|c|c|c|c|c|c|}
\hline \multirow{3}{*}{ Carr parameter } & & \multicolumn{3}{|c|}{ Angle } & \multicolumn{2}{|c|}{ Bulk density } & \multirow{3}{*}{$\begin{array}{c}\text { Compressibility } \\
\text { Co }\end{array}$} \\
\hline & & $\begin{array}{c}\text { repose } \\
\varphi_{\text {rep }}\end{array}$ & $\begin{array}{l}\text { fall } \\
\varphi_{\text {fall }}\end{array}$ & $\begin{array}{c}\text { difference } \\
\varphi_{\text {diff }}\end{array}$ & $\begin{array}{c}\text { aerated } \\
\rho_{\text {aer }}\end{array}$ & $\begin{array}{c}\text { packed } \\
\rho_{\text {pack }}\end{array}$ & \\
\hline & & \multicolumn{3}{|c|}{$\left({ }^{\circ}\right)$} & \multicolumn{2}{|c|}{$\left(\mathrm{kg} \mathrm{m}^{-3}\right)$} & \\
\hline \multirow{3}{*}{$\begin{array}{l}\text { Moisture } \\
\text { content (\%) }\end{array}$} & 6 & 38.1 & 26.7 & 11.4 & 763 & 986 & 22.6 \\
\hline & 12 & 46.1 & 18 & 28.1 & 697 & 918 & 24.1 \\
\hline & 17 & 58.4 & 41.1 & 17.3 & 593 & 850 & 30.2 \\
\hline \multirow{4}{*}{$\begin{array}{l}\text { Addition of } \\
\text { magnesium } \\
\text { stearate to } \\
\text { potato starch } \\
(\%)\end{array}$} & 0 & 38.1 & 26.7 & 11.4 & 763 & 986 & 22.6 \\
\hline & 1 & 41.9 & 24.7 & 17.2 & 691 & 980 & 29.5 \\
\hline & 2 & 43 & 29.8 & 13.2 & 700 & 982 & 28.7 \\
\hline & 6 & 40.9 & 22 & 18.9 & 688 & 976 & 29.5 \\
\hline
\end{tabular}


a

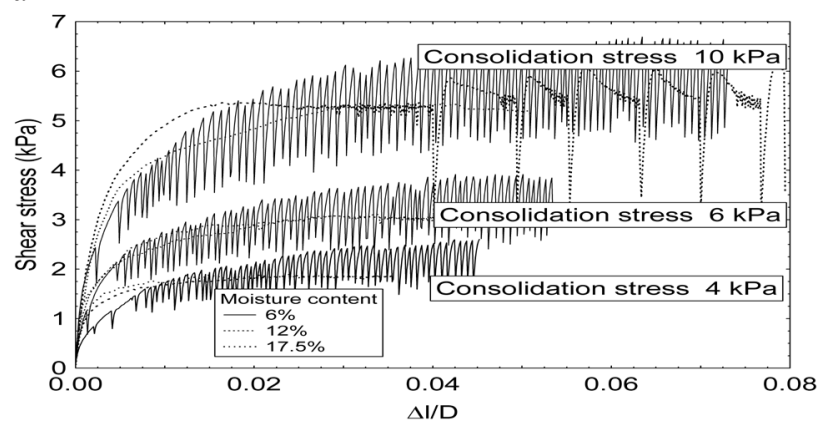

b

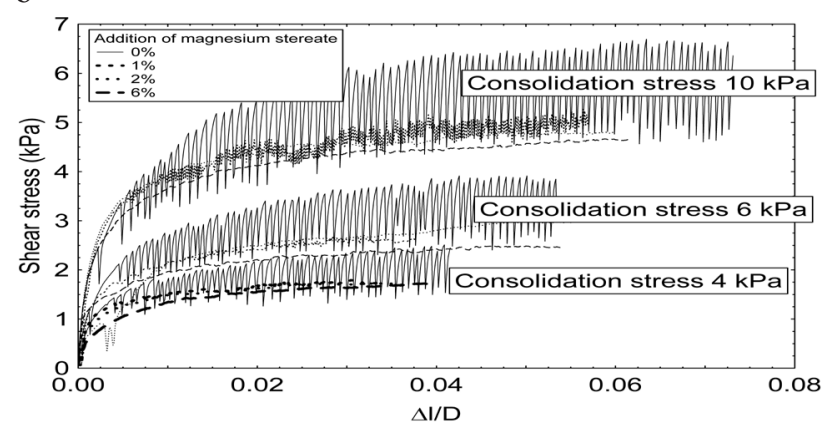

Fig. 4. Shear stress $\tau$ - relative displacement D1/D relationship of potato starch for: $\mathrm{a}$ - different moisture content and $\mathrm{b}$ - addition of magnesium stearate.

of powder materials which for thermal modified starches after drum or hot air drying is more rough than for native starch (Yadav et al., 2006). The highest amplitude of oscillations was observed for the highest consolidation pressure of $10 \mathrm{kPa}$. This result is typical for food powders and was obtained by Bagga et al. (2012) for cream powder. In their investigation for cream powder increase in normal load from 2.52 to $9.59 \mathrm{kPa}$ resulted in 6 fold higher amplitude of oscillations. Slip-stick effects cause difficulties in interpretation of testing results. Frictional parameters for materials showing fluctuations were estimated using the maximum values of shear stress to obtain the largest (or the worst case) values. As shown by Stasiak and Molenda (2004), it is also possible to reduce the slip-stick effects by a change in the stiffness of measurement equipment.

Increase in moisture content resulted in cessation of the slip-stick effect. Only small slip stick was observed for the highest normal stress of $10 \mathrm{kPa}$ for moisture content of $12 \%$. Probably water which is on the surface of granules acts as a lubricant, allowing smooth sliding. Moreover. increase in moisture content resulted in earlier stabilization of experimental curves. Addition of magnesium stearate resulted in lower values of maximum stable values of shear stresses. Moreover, even the lowest addition of the lubricant of $1 \%$ resulted in disappearance of the slip-stick effect.
Angle of internal friction $\varphi$ was found to be influenced by moisture content and addition of magnesium stearate as shown in Fig. 5. Average values of $\varphi$ decreased sharply with an increase in moisture content, from approximately $25^{\circ}$ for $6 \%$ moisture content to approximately $16^{\circ}$ for $12 \%$ moisture content. For $17 \%$ moisture content a slight decrease was observed, to $14^{\circ}$. Probable reason of such behaviour was that the powder reaches the state of saturation and water acts as a lubricant. For the highest moisture content, free water may appear on the surface of granules and decrease friction in contacts. It is opposite behaviour to that determined in Hosokawa Powder Tester, where the angle of repose increased with an increase in moisture content. These results are in agreement to results obtained by Guan and Zhang (2009) which determined higher angle of internal friction $\varphi$ for drier material.

In the case of 1 and $2 \%$ addition of the lubricant, angle of internal friction decrease from approximately 28 to $16^{\circ}$ was observed. The lowest value of the angle of internal friction was obtained for the highest addition of the lubricant. Also these results are opposite to the behaviour of angle of repose observed in HPT. The reason for this difference in frictional behaviour is probably the difference of level of pressure, nearly zero (own weight) in testing in free fall and maximum $10 \mathrm{kPa}$ in direct shear test.
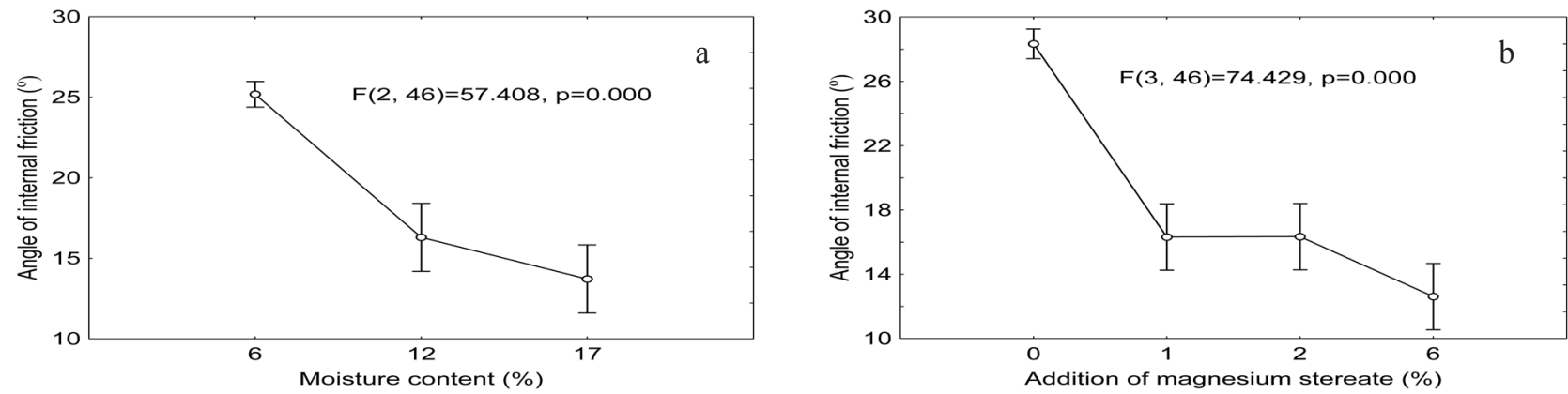

Fig. 5. Relationships between angle of internal friction at: $\mathrm{a}$ - different moisture content and $\mathrm{b}$ - addition of magnesium stearate. Points denote mean values and vertical bars denote the 0.95 confidence interval; F, p - analysis of variance parameters. The higher value of test function $\mathrm{F}$ means than given effect has stronger influence on determined parameter. The p-value is significance. 
a

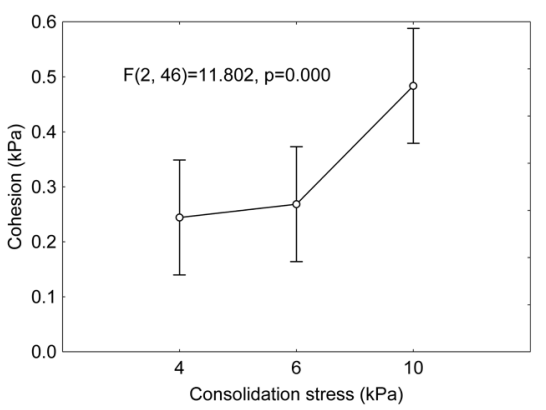

b

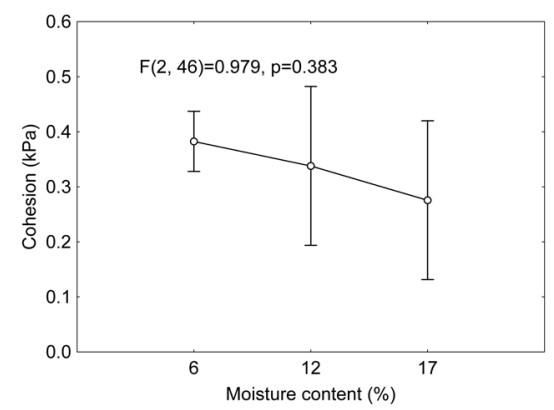

c

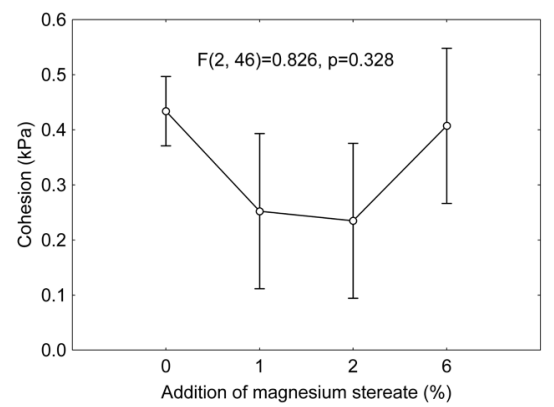

Fig. 6. Relationships between: $\mathrm{a}$ - cohesion and consolidation stress, $\mathrm{b}$ - cohesion and moisture content, and c - cohesion and addition of the lubricant. Explanations as in Fig. 5.

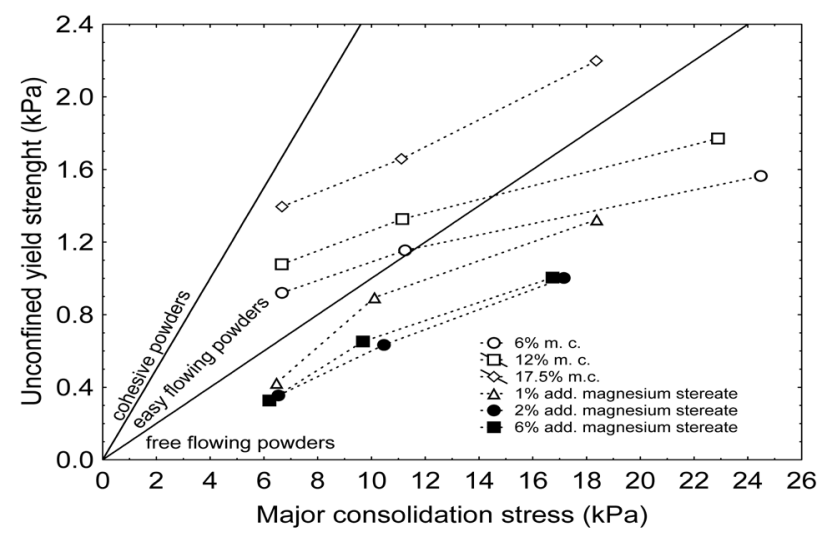

Fig. 7. Flow functions of examined powders of potato starch.
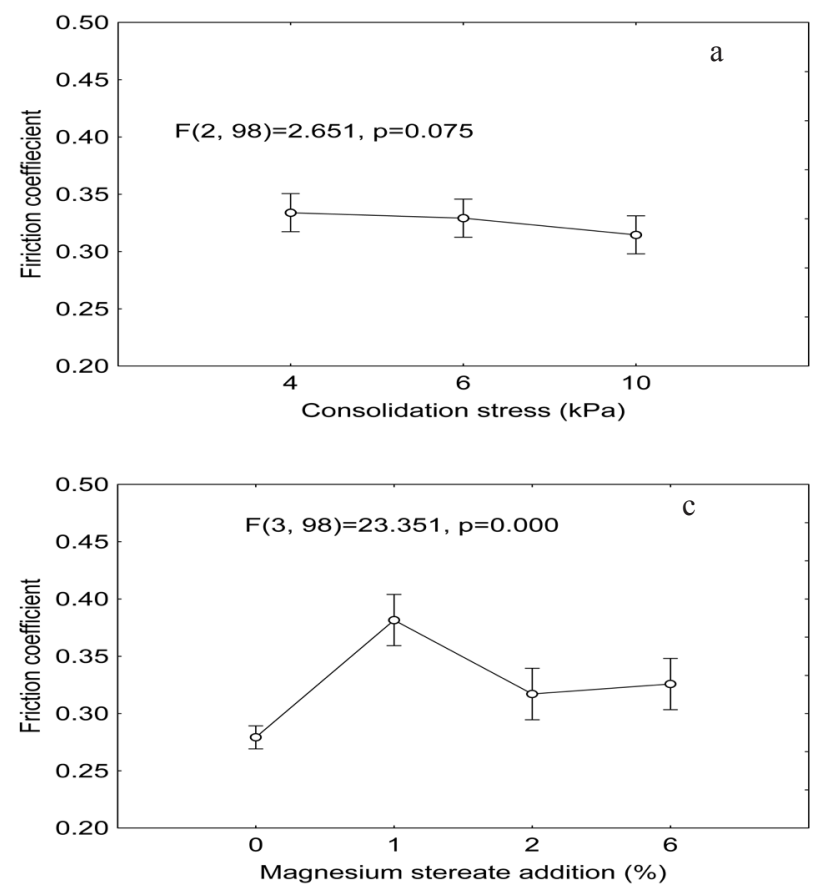

Cohesion increased with consolidation stress from approximately $0.25 \mathrm{kPa}$ to approximately $0.5 \mathrm{kPa}$ with an increase in consolidation stress. No influence of moisture content on cohesion was observed (Fig. 6).

Addition of the lubricant in an amount of $1 \%$ resulted in a decrease in cohesion and angle of internal friction. Reaching 6\% concentration, cohesion increased almost to the value obtained when no lubricant was present.

Significant differences in FF of examined samples were observed as shown in Fig. 7. Values of FF were characteristic for free and easy flowing materials.

Values of FF increased by $50 \%$ with an increase in moisture content from approximately 0.9 to $1.4 \mathrm{kPa}$ for the lowest consolidation stress, and from approximately 1.6 to $2.2 \mathrm{kPa}$ for consolidation stress of $10 \mathrm{kPa}$. In the case of addition of magnesium stearate a significant decrease in FF value was observed. For consolidation stress of $4 \mathrm{kPa}$ the
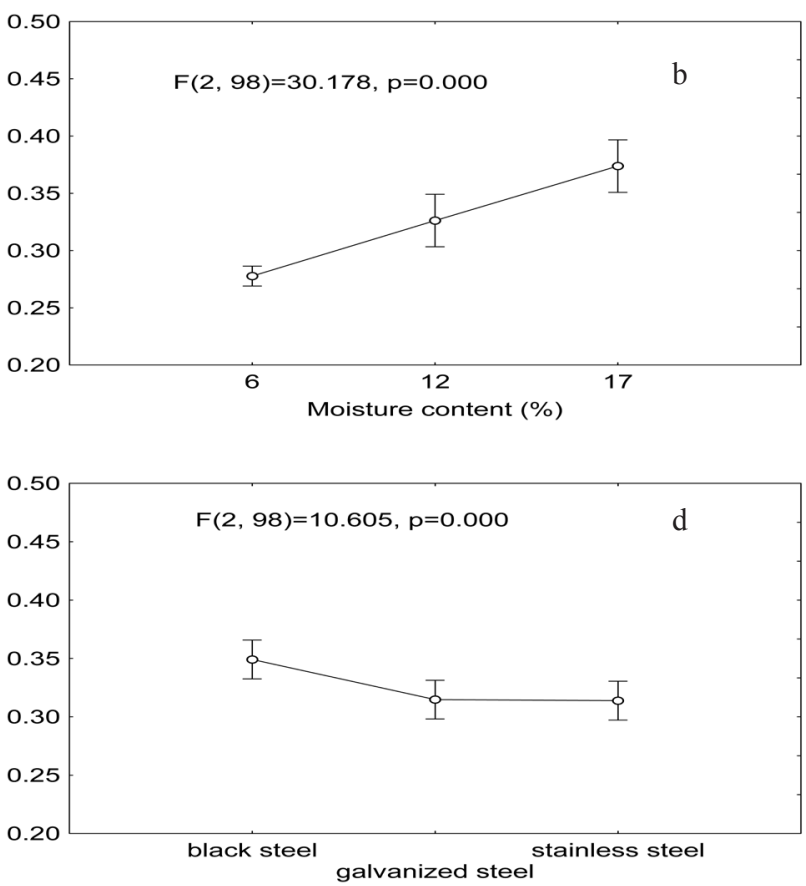

Fig. 8. Coefficient of friction of potato starch as dependent on: a - consolidation stress, b - moisture content, c - amount of lubricant added and d - type of steel. Explanations as in Fig. 5. 
values of unconfined yield strength decreased from $0.9 \mathrm{kPa}$ to approximately $0.4 \mathrm{kPa}$ for each concentration of magnesium stearate. In the case of the highest value of consolidation stress the values of FF decreased roughly by $25 \%$ for the addition of $1 \%$ of magnesium stearate. For 2 and $6 \%$ of lubricant addition the FF decreased by about $50 \%$. Mechanical strength of the bed and worsening powder flowability with an increase of moisture content were observed by Opaliński et al. (2012).

Coefficient of friction was determined against construction materials widely used in industrial technologies, three kind of steel: black, galvanized and stainless. Average values of friction coefficient are presented in Fig. 8. The highest friction coefficient of the tested materials was observed for black steel, while values obtained for galvanized and stainless steel were nearly equal. No significant differences in friction coefficient were observed at various consolidation stresses. Coefficient of friction increased by approximately $40 \%$ with increasing moisture content.

\section{CONCLUSIONS}

1. Values of mechanical parameters of potato starch were found to be strongly influenced by moisture content of the material and amount of lubricant added.

2. During loading of the starch with addition of $1 \%$ of lubricant, the modulus of elasticity decreased with increase in moisture content. Further increase in the content of lubricant did not influence the elasticity. During unloading the modulus of elasticity did not change with increase in moisture content and increased with increase in addition of magnesium stereate.

3. Slip-stick effect observed during experiments decreased with increase of moisture content and addition of magnesium stearate.

4. Angle of internal friction decreased with increase in water content in whole range of moisture content and even minimum addition of lubricant, while practically no considerable influence was observed in the case of cohesion.

5. Values of flow function increased with increase in moisture content and decreased with addition of lubricant.

6 . The highest friction coefficient was observed for black steel. No influence of consolidation stress on the friction coefficient was observed. Strong increase in friction coefficient with increase in moisture content was noted. Addition of magnesium stearate resulted in increase in friction coefficient.

\section{REFERENCES}

Abdo J., Tahat M., Abouelsoud A., and Danish M., 2010. The effect of frequency of vibration and humidity on the stick - slip amplitude. Int. J. Mechanics Materials in Design, 6, 645-651.

Ahmad M.Z., Akhter S., Anvar M., Rahman M., Siddiqui M.A., and Ahmad F.J., 2012. Compactibility and compressibility studies of Assam Bora rice starch. Powder Technol., 224, 281-286.
Bagga P., Brisson G., Baldwin A., and Davies C.E., 2012. Stickslip behaviour of dairy powders: Temperature effect. Powder Technol., 223, 46-51.

Baldwin P.M., Adler J., Davies M.C, and Melia C.D., 1998. High resolution imaging of starch granule surfaces by atomic force microscopy. J. Cereal Sci., 27, 255-265.

Barletta D. and Poletto M., 2013. A device for the measurement of the horizontal to vertical stress ratio I powders. Granular Matter, 15(4), 487-497.

Bieganowski A., Krusińska A., and Ryżak M., 2011. A method for the elimination of measurement error in light microscopy examinations of the geometry of starch granules. Int. Agrophys., 25, 193-196.

Bos C.E., Bolhuis G.K., van Doorne H., and Lerk C.F., 1987. Native starch in tablet formulations: properties on compaction. Pharma ceutisch Weekblad scientific Edition, 9, 274-282.

Carr R.L., 1965. Evaluating flow properties of solids. Chemical Eng., 72, 163-168.

Chujiang C., Jinzhi L., Zhigang S., Shulin M., and Yushan X., 2009. Synthesis of hydrophobic corn starch with high flowability by surface modification. Starch/Starke, 61, 344-351.

Crouter A. and Briens L., 2014. The effect of moisture on the flowability of pharmaceutical excipients. AAPS Pharmaceutical Sci. Technol., 15 (1), 65-74.

Cuq B., Rondet E., and Abecassis J., 2011. Food powder engineering, between knowhow and science: Constraints, stakes and opportunities. Powder Technol., 208(2), 244-251.

Di Qu A. and Wang S.S., 1998. Modelling shearing resistance of powdery starch for simulation Studies of extrusion cooking processes. Starch/ Starke, 50/1, 147-153.

Eurocode 1, Part 4, 2006. Basis of design and actions on structures. Actions in silos and tanks. EN 1991-4.

Fitzpatrick J.J. and Ahrne L., 2005. Food powder handling and processing: industry problems, knowledge barriers and research opportunities. Chemical Eng. Proc., 44, 209-214.

Guan W. and Zhang Q., 2009. The effect of moisture content and compaction on the strength and arch formation of wheat flour in model bin. J. Food Eng., 94, 227-232.

Kamika Operation Guide, 2009. Kamika Instruments, Warsaw, Poland.

Mazurkiewicz J., 2011. Fractal dimension and rheological properties of cereal starches. Int. Agrophys., 25, 249-255.

Mitrus M. and Mościcki L., 2009. Physical properties of thermoplastic starches. Int. Agrophys., 23, 305-308.

Molenda M., Stasiak M., Horabik J., Fornal J., Blaszczak W., and Ornowski A., 2006. Microstructure and mechanical parameters of five types of starch. Polish J. Food Nutrition Sci., 5/56(2), 161-168

Mościcki L., Mitrus M., Wójtowicz A., Oniszczuk T., Rejak A., and Janssen L., 2012. Application of extrusion-cooking for processing of thermoplastic starch (TPS). Food Res. Int., 47, 291-299.

Moya M., Aguado P.J., and Ayuga F., 2013. Mechanical properties of some granular agricultural materials used in silo design. Int. Agrophys., 27, 181-193.

Nokhodchi A., 2005. An overview of the effect of moisture on compaction and compression. Pharmaceutical Technol., 1, 46-66. 
Odeku O.A., Awe O.O., Popoola B., Odeniyi M.A., and Itiola O.A., 2005. Compression and mechanical properties of tablet formulations containing corn, sweet potato and cocoyam starches as binders. Pharmaceutical Technol., 4, 82-90.

Opaliński I., Chutkowski M., and Stasiak M., 2012. Characterizing most food-powder flowability using Jenike sheartester. J. Food Eng., 108, 51-58.

Ramírez A., Moya M., and Ayuga F., 2009. Determination of the mechanical properties of powdered agricultural products and sugar. Part. Part. Sys. Charact., 26(4), 220-230.

Ruppel J., Muller A.K., Althaus G., Drexel C.P., and Zimmermann I., 2009. The modified outflow funnel - A device to assess the flow characteristics of powders. Powder Technol., 193, 87-92.

Salerno M., Żukowska A., Thorat S., Rufilli R., Stasiak M., and Molenda M., 2014. High resolution imaging of native wheat and potato starch granules based on local mechanical contrast. J. Food Eng., 128, 69-102.

Schroeter J. and Hobelsberger M., 1992. On the mechanical properties of native starch granules. Starch/Starke, 44,7, 247-252.

Singh N., Singh J., Kaur R., Sodhi N.S., and Gill B.S., 2003. Morphological, thermal and rheological properties of starches from different botanical sources. Food Chem., 81, 219-231.
Stasiak M. and Molenda M., 2004. Direct shear testing of food powders flowability - influence of deformation speed and apparatus stiffness. Acta Agrophysica, 4, 557-564.

Stasiak M., Molenda M., and Horabik J., 2007. Determination of modulus of elasticity of cereals and rapeseeds using acoustic method. J. Food Eng., 82, 51-57.

Stasiak M, Rusinek R., Molenda M., Fornal J., and Blaszczak W., 2011. Effect of potato starch modification on mechanical parameters and granules morphology. J. Food Eng., 102, 154-162.

Stasiak M., Tomas J., Molenda M., Rusinek R., and Mueller P., 2010. Uniaxial compaction behavior and elasticity of cohesive powders. Powder Technol., 203, 482-488.

Wang J., Wen H., and Desai D., 2010. Lubrication in tablet formulations. European J. Pharmaceutics Biopharmaceutics, $75,1-15$.

Yadav A.R., Guha M., Tharanathan R.N., and Ramteke R.S., 2006. Influence of drying conditions on functional properties of potato flour. European Food Res. Technol., 223, 553-560.

Zavareze E.R., Pinto V.Z., Klein B., Halal S.L.M., Elias M.C., Prentice-Hernandez C., and Dias A.R.G., 2012. Development of oxidized and heat-moisture treated potato starch film. Food Chem., 132, 344-350. 